\title{
Pengaruh Pendekatan Sains Teknologi Masyarakat (STM) Terhadap Peningkatan Hasil Belajar Siswa Pada Sub Materi Pemanfaatan Struktur Tumbuhan Dalam Teknologi
}

\author{
Supardi Abram ${ }^{1 *}$, Anneke T. Rondonuwu ${ }^{2}$ \\ 1,2 Jurusan Pendidikan IPA, FMIPA, Universitas Negeri Manado \\ *e-mail: abramsupardi@gmail.com
}

\begin{abstract}
Abstrak. Penelitian ini bertujuan untuk mengetahui pengaruh pendekatan sains teknologi masyarakat terhadap peningkatan hasil belajar siswa kelas VIII SMP Negeri Daerah Kotabunan pada sub materi pemanfaatan struktur tumbuhan dalam teknologi. Penelitian ini merupakan penelitian eksperimen semu, menggunakan rancangan penelitian pretest-posttest control group design. Populasi dalam penelitian ini adalah seluruh kelas VIII di SMP Negeri Daerah Kotabunan dan sampel penelitian terdiri dari dua kelas yaitu kelas VIII A sebagai kelas eksperimen yang berjumlah 20 siswa dan kelas VIII B sebagai kontrol yang berjumlah 20 siswa. Pengambilan data dilakukan dengan memberikan pretest sebelum proses penelitian dilaksanakan dan posttest sesudah diberikan perlakuan. Data hasil penelitian yang diperoleh berupa nilai ratarata hasil pretest dan posttest pada kelompok eksperimen 26,55 dan 59.5 sedangkan untuk kelompok kontrol nilai rata-rata hasil pretest dan posttest adalah 23,85 dan 73,1 . Setelah diuji statistik melalui uji-t, rata-rata hasil belajar yang didapat antara kelompok eksperimen dan kelompok kontrol yaitu thitung $=8,063>t_{\text {tabel }}=1,304$. Dengan demikian dapat disimpulkan bahwa terdapat pengaruh pendekatan sains teknologi masyarakat terhadap peningkatan hasil belajar siswa kelas VIII SMP Negeri Daerah Kotabunan pada sub materi pemanfaatan struktur tumbuhan dalam teknologi.

Kata kunci: pendekatan sains teknologi masyarakat, hasil belajar, pemanfaatan struktur tumbuhan dalam teknologi
\end{abstract}

\begin{abstract}
This study aims to determine the effect of the science technology society approach to improving student learning outcomes in class VIII SMP Negeri Kotabunan on the sub-material of the use of plant structures in technology. This research is a quasiexperimental research, using a pretest-posttest control group design. The population in this study was all class VIII at SMP Negeri Kotabunan and the research sample consisted of two classes, namely class VIII A as the experimental class with 20 students and class VIII B as control with 20 students. Data were collected by giving a pretest before the research process was carried out and a posttest after being given treatment. The research data obtained in the form of the average value of the pretest and posttest results in the experimental group is 26.55 and 59.5, while for the control group the average value of the pretest and posttest results is 23.85 and 73.1. After being tested statistically through the t-test, the average learning outcomes obtained between the experimental group and the control group were $t_{\text {count }}=8.063>t_{\text {table }}=1.304$. Thus, it can be concluded that there is an effect of the science technology society approach on improving student learning outcomes for class VIII SMP Negeri Kotabunan in the sub-material of the use of plant structures in technology.
\end{abstract}

Keywords: science technology society, learning outcomes, utilizing plant structure in technology 


\section{PENDAHULUAN}

Pendidikan merupakan salah satu sarana yang sangat penting dalam kehidupan manusia, karena melalui pendidikan akan dapat menciptakan manusia yang berpotensi, kreatif, dan memiliki ide cemerlang sebagai bekal untuk memperoleh masa depan yang lebih baik. Pendidikan juga merupakan salah satu usaha untuk meningkatkan sumber daya manusia dalam menyesuaikan diri dari perkembangan ilmu pengetahuan dan teknologi.

Belajar adalah proses perubahan perilaku, berkat interaksi dengan lingkungannya (Hanafiah \& Suhana, 2009), demikian juga dengan belajar Ilmu Pengetahuan Alam (IPA), siswa akan mudah mempelajari konsep yang lebih baik jika belajar IPA langsung berinteraksi dengan lingkungan sehingga materi yang diberikan mudah dipahami dan dikuasai dengan baik, sehingga proses pembelajaran harus dirancang dengan baik agar siswa dapat mencapai tujuan sesuai yang diharapkan.

Berdasarkan observasi dalam mempelajari IPA khususnya di kelas VIII, guru masih menggunakan pendekatan konvensional (ceramah), sehingga siswa kurang serius dalam menerima pembelajaran, siswa sering keluar kelas dalam proses pembelajaran, siswa kurang aktif dalam memberikan pertanyaan kepada guru, kurangnya rasa ingin tahu siswa terhadap suatu permasalahan yang di hadapkan tidak adanya inisiatif sendiri dari siswa sehingga berdampak pada rendahnya hasil belajar siswa dan proses belajar siswa yang kurang menarik, sehingga hanya sebagian siswa yang mencapai kentutasan belajar. Hal ini dapat di lihat dari nilai ulangan harian siswa yang di peroleh rata-rata $\leq 71$, dengan siswa yang tuntas 62\%. Sedangkan nilai Kriteria Ketuntasan Minimum (KKM) yang di tetapkan oleh sekolah yaitu 73. Untuk itu guru dituntut agar menggunakan pendekatan pembelajaran yang tepat dengan materi yang diberikan kepada siswa agar hasil pembelajaran mencapai tujuan seperti yang diharapkan dan disenangi oleh siswa.
Upaya mengatasi masalah belajar siswa tersebut perlu dilakukan suatu perubahan pendekatan dalam pembelajaran. Salah satu pendekatan yang digunakan dalam pembelajaran yaitu pendekatan Sains Teknologi Masyarakat (STM). Usaha mengaitkan sains dengan kehidupan sehari-hari adalah dengan pendekatan STM. Pendekatan STM merupakan pendekatan pembelajaran yang dirancang dengan menggunakan isu-isu sosial dan teknologi yang ada di lingkungan siswa sebagai pemicu dalam pembelajaran suatu konsep.

Ketika mempelajari IPA unsur pemahaman atau pengertian lebih dominan dari pada unsur hafalan. Pendidik harus mampu menggunakan pendekatan yang sesuai dengan materi yang diajarkan, dengan melakukan suatu perubahan pendekatan dalam pembelajaran, salah satunya adalah penerapan pendekatan STM. Pendekatan STM memiliki keuntungan yaitu relevan untuk masyarakat mendatang, karena siswa sekarang akan hidup di dunia yang didominasi oleh manifestasi dari ilmu dan teknologi dan juga relevan terhadap kehidupan sehari-hari. Bagaimanapun, ilmu pengetahuan yang relevan dengan kehidupan sehari-hari akan menarik dan memotivasi siswa untuk lebih aktif lagi (Thabrany dalam Azhari, 2014).

Tujuan pembelajaran IPA yang berwawasan pendekatan STM ini adalah untuk memberikan pengetahuan tentang lingkungan alam, pengembangan keterampilan. Pembelajaran IPA harus dapat menciptakan suatu kondisi dimana siswa harus mampu memadukan pemahamannya tentang dunia alam (IPA) dengan dunia buatan manusia (teknologi) dan dunia sosial dari pengalaman siswa sehari-hari (masyarakat). Pembelajaran IPA yang berwawasan pendekatan STM dapat menumbuh kembangkan sikap IPA dan teknologi siswa. IPA tidak hanya berupa IPA yang bersifat ingatan, melainkan IPA yang berkaitan dengan sekitar siswa dan dapat diaplikasikan dengan pengalaman belajar siswa dalam kehidupan sehari-hari, sehingga 
pendekatan STM sangat cocok untuk digunakan pada proses pembelajaran dengan sub materi pemanfaatan struktur tumbuhan dalam teknologi karena pada proses pembelajaran peneliti mengaitkan materi ini dengan isu-isu sosial dan teknologi yang pada masyarakat atau lingkungan siswa sebagai pemicu dalam pembelajaran.

Berdasarkan uraian diatas, peneliti melakukan penelitian yang bertujuan untuk mengetahui pengaruh pendekatan Sains Teknologi Masyarakat (STM) terhadap peningkatan hasil belajar siswa kelas VIII SMP Negeri Daerah Kotabunan pada sub materi pemanfaatan struktur tumbuhan dalam teknologi.

\section{METODE PENELITIAN}

Penelitian ini dilaksanakan di kelas VIII SMP Negeri Daerah Kotabunan dan waktu penelitian ini dilaksanakan pada bulan oktober semester ganjil tahun ajaran 2020/2021. Metode penelitian yang digunakan dalam penelitian ini adalah metode eksperimen. Metode eksperimen dapat diartikan sebagai metode penelitian untuk mencari pengaruh treatment/perlakuan (Sugiyono, 2017).

Tabel 1. Desain penelitian

\begin{tabular}{llll}
\hline Kelompok & Pretest & Perlakuan & Posttest \\
\hline Eksperimen & $\mathrm{O}_{1}$ & $\mathrm{X}$ & $\mathrm{O}_{2}$ \\
Kontrol & $\mathrm{O}_{3}$ & - & $\mathrm{O}_{4}$ \\
\hline \multicolumn{2}{c}{ (Sugiyono, 2017) }
\end{tabular}

Desain penelitian pada Tabel 1 menunjukkan kelompok eksperimen yang diberikan perlakuan dengan menerapkan pendekatan STM dalam pembelajaran (X) sedangkan pada kelompok kontrol menerapkan pembelajaran konvensional. Setiap kelompok diberikan pretest untuk kelas eksperimen $\left(\mathrm{O}_{1}\right)$ dan pretest untuk kelas kontrol $\left(\mathrm{O}_{3}\right)$ sedangkan posttest untuk kelas eksperimen $\left(\mathrm{O}_{2}\right)$ dan posttest untuk kelas kontrol $\left(\mathrm{O}_{4}\right)$.

Dalam mengumpulkan data pada penelitian ini, peneliti melakukan beberapa tahap prosedur penelitian sebagai berikut: (1) Menentukan populasi dan sampel penelitian. (2) Menentukan pokok bahasan yang akan dipergunakan dalam penelitian pendekatan STM. (3)
Menyusun instrumen penelitian berupa tes dalam bentuk soal essay. (4) Melaksanakan eksperimen dengan langkah-langkah sebagai berikut: a) Menentukan kedua kelompok yaitu eksperimen dan kontrol, kelompok eksperimen menggunakan pendekatan STM sebanyak satu kelas dan kelompok kontrol menggunakan pendekatan pembelajaran konvensional sebanyak satu kelas. b) Melaksanakan pretest pada hari yang sama pada dua kelas yaitu kelas eksperimen dan kelas kontrol. Soal pretest yang digunakan dalam penelitian ini berbentuk essay, tahapan tersebut bertujuan untuk mengetahui keadaan awal antara kedua kelas eksperimen dan kontrol. c) Melakukan kegiatan pembelajaran sesuai dengan RPP (dengan frekuensi pertemuan disesuaikan dengan silabus) pada kedua kelas eksperimen dan kontrol dengan alokasi waktu 2 x 40 menit. d) Melaksanakan perlakuan kepada kelas eksperimen dengan menggunakan pendekatan pembelajaran STM dan kepada kelas kontrol menggunakan pendekatan pembelajaran konvensional. e) Melaksanakan posttest pada hari yang sama pada kedua kelas eksperimen dan kontrol. Soal posttest yang digunakan dalam penelitian ini berbentuk tes essay, tahapan ini bertujuan untuk melihat hasil akhir dari kedua kelas yaitu kelas eksperimen dan kelas kontrol.

Data hasil belajar siswa dikumpulkan dengan memberikan tes sebelum dan tes sesudah pembelajaran selesai pada materi IPA, sebelum tes tersebut diberikan terlebih dahulu diuji validitas dan reliabilitas. Setelah data terkumpul, maka dilakukan analisis data dengan menggunakan pendekatan statistik untuk menetukan hasil belajar dengan menggunakan uji-t.

Instrumen yang digunakan sebagai alat untuk memperoleh data yang diperlukan oleh peneliti dalam kegiatan penelitian yaitu observasi dan tes. Tes yang digunakan yaitu tes essay, sebelum instrumen hasil belajar tersebut digunakan terlebih dahulu sudah dilakukan uji validitas dengan $\mathrm{H}_{0}=$ ratarata hasil belajar IPA pada sub materi 
pemanfaatan struktur tumbuhan dalam teknologi dengan mengunakan pendekatan STM $\left(\mu_{1}\right)$ lebih rendah atau sama dengan rata-rata hasil belajar IPA siswa dengan mengunakan model pembelajaran konvensional $\left(\mu_{2}\right)$ dan $\mathrm{H}_{\mathrm{a}}=$ rata-rata hasil belajar IPA pada sub materi pemanfaatan struktur tumbuhan dalam teknologi dengan mengunakan pendekatan STM $\left(\mu_{1}\right)$ lebih tinggi dari hasil belajar IPA siswa dengan mengunakan model pembelajaran konvensional $\left(\mu_{2}\right)$.

\section{HASIL DAN PEMBAHASAN}

Data hasil penelitian ini diambil dari dua kelas di SMP Negeri Daerah Kotabuan yaitu kelas VIII A sebagai kelas eksperimen yang berjumlah 20 orang dan kelas VIII B sebagai kelas kontrol yang berjumlah 20 orang. Data yang diambil adalah hasil belajar siswa pada sub materi pemanfaatan struktur tumbuhan dalam teknologi yang di ambil dari posttest. Kegiatan pertama yang dilakukan adalah melakukan tes awal (pretest) terhadap masing-masing kelas. Tes awal dilakukan untuk mengetahui kemampuan awal siswa sebelum dilakukan perlakuan. Setelah dilakukan perlakuan selanjutnya diberi tes akhir (posttest) kepada masing-masing kelas untuk mengetahui apakah ada peningkatan hasil belajar siswa setelah diberikan perlakuan. Ketercapaian penguasaan materi dilihat pada saat posttest.

Tabel 2. Skor hasil belajar siswa kelas eksperimen

\begin{tabular}{lll}
\hline Statistik & Pretest & Posttest \\
\hline Jumlah & 531 & 1690 \\
Skor maksimum & 43 & 91 \\
Skor minimum & 15 & 73 \\
Nilai rata-rata & 26,55 & 84,5 \\
Standar deviasi & 7,85 & 5,88 \\
Varians & 61,73 & 130,26 \\
\hline
\end{tabular}

Berdasarkan Tabel 2 hasil pretest dan posttest pada kelas eksperimen dengan nilai rata-rata pretest 26,55 dan posttest 84,5 dengan standar deviasi pretest 7,85 dan posttest 5,53 dengan varians pretest 61,73 dan posttest 30.681 .
Tabel 3. Skor hasil belajar siswa kelas kontrol

\begin{tabular}{lll}
\multicolumn{3}{c}{ kontrol } \\
\hline Statistik & Pretest & Posttest \\
\hline Jumlah & 477 & 1462 \\
Skor maksimum & 40 & 82 \\
Skor minimum & 15 & 60 \\
Nilai rata-rata & 23,85 & 73,1 \\
Standar deviasi & 6,45 & 6,06 \\
Varians & 41,60 & 36,72 \\
\hline
\end{tabular}

Berdasarkan Tabel 3, nilai rata-rata pada kelompok kontrol untuk pretest 23.85 dan posttest 73.1 dengan standar deviasi pretest 6,45 dan posttest 6,06 dengan varians pretest 41,60 dan posttest 36,72 .

Maka, hipotesis dari hasil pengujian dengan melakukan uji-t diperoleh thitung $=$ 8,063 dan $t_{\text {tabel }}=1,686$, dengan kriteria pengujian jika thitung $>$ tabel maka $\mathrm{H}_{0}$ ditolak dan $\mathrm{H}_{\mathrm{a}}$ diterima. Dengan demikian, rata-rata hasil belajar pada sub materi pemanfaatan struktur tumbuhan dalam teknologi yaitu kelas eksperimen dengan menggunakan pendekatan STM lebih baik karena memiliki pengaruh pada peningkatan hasil belajar siswa dilihat dari data rata-rata hasil belajar.

Ketika diberikan pembelajaran menggunakan pendekatan STM yang mana mengaitkan materi dengan teknologi yang ada di lingkungan sekitar siswa mampu membuat siswa mudah menerima materi yang dijelaskan sehingga dalam proses belajar, yang aktif bukan hanya guru saja tetapi siswa juga begitu aktif dan juga mengurangi rasa bosan siswa untuk belajar tentang IPA, dibandingkan dengan rata-rata hasil belajar pada kelas kontrol dengan menggunakan pendekatan konvensional nilai rata-rata masih standar tidak ada peningkatan sebab dalam proses pembelajaran hanya guru saja yang aktif tidak mengaitkan siswa sehingga siswa begitu bosan menerima pembelajaran. Sehingga sesuai dengan hasil yang diperoleh dalam penelitian ini, pendekatan STM berpengaruh meningkatkan hasil belajar siswa.

Hasil yang didapatkan dari penelitian ini bersesuaian dengan penelitian sebelumnya yang dilakukan oleh Hunaepi, Samsuri, Asy'ari \& 
Sukaisih (2014), yang mengemukakan bahwa STM dapat diartikan sebagai pendekatan pembelajaran yang dirancang dengan menggunakan isu- isu sosial dan teknologi yang ada di lingkungan siswa sebagai pemicu dalam pembelajaran suatu konsep. Dari hasil analisis menunjukan bahwa setelah menggunakan pendekatan STM, hasil belajar siswa mengalami peningkatan. Hal ini juga sejalan dengan penelitian sebelumnya yang dilakukan oleh Renold, Jamhari \& Rede (2013), Sari \& Hairida (2016), Suteja \& Wijayanti (2017), Aswadi (2017), Budi \& Sunarno (2018), Asikin, Irawati \& Syamsuri (2017) dan Mun'im, Yunus \& Aksa (2019), yang menyatakan bahwa pendekatan STM merupakan salah satu pendekatan yang cocok digunakan dalam pembelajaran karena dapat meningkatkan hasil belajar siswa.

\section{KESIMPULAN}

Berdasarkan hasil penelitian dan pembahasan, dapat disimpulkan bahwa pendekatan Sains Teknologi Masyarakat (STM) berpengaruh terhadap peningkatan hasil belajar siswa kelas VIII SMP Negeri Daerah dimana rata-rata hasil belajar siswa menggunakan pendekatan STM lebih baik dari rata-rata hasil belajar menggunakan pendekatan konvensional.

\section{DAFTAR PUSTAKA}

Asikin, N., Irawati, M. H., \& Syamsuri, I. (2017). Pembelajaran Biologi Berpendekatan Saintifik Model Sains Teknologi Masyarakat Untuk Meningkatkan Hasil Belajar Siswa. Pedagogi Hayati, 1(1), 1-10.

Aswadi. (2017). Penerapan Sains Teknologi Masyarakat (STM) Untuk Meningkatkan Hasil Belajar Siswa Pada Kelas VII MTS Nurul IlmiRanggagata Tahun pelajaran 2016/2017. Skripsi. Universitas Islam Negeri (UIN) Mataram.

Azhari, E. (2014). Penerapan Pendekatan Sains Teknologi Masyarakat (STM) pada Konsep Energi dan Daya di Kelas XI SMA Negeri 12 Banda Aceh. Skripsi. UIN Ar-Raniry Banda Aceh.

Budi, A. P. S., \& Sunarno, W. (2018, May). Natural Science Modules With SETS
Approach To Improve Students' Critical Thinking Ability. In Journal of Physics: Conference Series (Vol. 1022, No. 1, p. 012015). IOP Publishing.

Hanafiah, N., \& Suhana, C. (2009). Konsep Strategi Pembelajaran. Bandung: Refika Aditama.

Hunaepi, Samsuri, T., Asy'ari, M., \& Sukaisih, R. (2014). Sains Teknologi Masyarakat: Strategi, Pendekatan dan Model Pembelajaran. Mataram: Duta Pustaka Ilmu.

Mun'im, A., Yunus, S. R., \& Aksa, A. (2019). Pengaruh Pendekatan Sains Teknologi Masyarakat (STM) Terhadap Motivasi dan Hasil Belajar Peserta Didik Kelas VIII SMP Negeri 1 Pangkajene (Studi Pada Materi Pokok Pesawat Sederhana). Jurnal IPA Terpadu, 3(1), 31-38.

Renold, R., Jamhari, M., \& Rede, A. (2013). Meningkatkan Hasil Belajar Siswa Melalui Pendekatan Sains Teknologi Masyarakat (STM) Pada Pelajaran IPA Pokok Bahasan Daur Air Siswa Kelas V SDN 2 Dataran Bulan. Jurnal Kreatif Online, 1(2).

Sari, I. N., \& Hairida, R. M. (2016). Penerapan Model Sains Teknologi Masyarakat (STM) Sub Pokok Bahasan Pestisida di Kelas VIII SMP Negeri 8 Ketapang. Jurnal Pendidikan Informatika dan Sains, 3(1), 41-50.

Sugiyono. (2017). Metode Penelitian Kuantitatif, Kualitatif, dan $R \& D$. Bandung: Alfabeta.

Suteja, I. P., \& Wijayanti, A. (2017). Pendekatan Sains Teknologi Masyarakat Terhadap Hasil Belajar IPA Siswa Kelas VIII. NATURAL: Jurnal Ilmiah Pendidikan IPA, 4(1), 16. 